\title{
POLÍTICAS CULTURAIS EM MOÇAMBIQUE ENTRE IDENTIDADE NACIONAL E INSTÂNCIAS LOCAIS (1975-2009) ${ }^{1}$
}

Cultural Policies in Mozambique between National Identity and Local Instances (1975-2009)

BUSSOTTI, Luca. ${ }^{2}$

GUNDANE, Reginaldo Albino ${ }^{3}$

\begin{abstract}
Resumo: Este artigo tem como objectivo analisar a implementação das políticas culturais em Moçambique de 1975 a 2009. Apesar de muitos esforços, os resultados conseguidos foram modestos. A implementação das políticas culturais em Moçambique pode ser subdividida em três gerações ou fases, nomeadamente a consolidação da identidade e preservação do património, a regulação econômica do setor cultural e a produção e difusão do setor cultural. A abordagem metodológica adotada foi de tipo qualitativo, centrada na análise documental e legislativa do material disponível, segundo uma perspectiva histórica. 0 que resultou da investigação foi que no período socialista a política cultural expressava uma visão enraizada numa ideologia clara (o socialismo), que porém não considerou adequadamente as instâncias culturais a nível local, ao passo que, com a "Segunda República", o Estado se tornou cada vez menos interventivo e mais regulador, deixando largo espaço às forças do mercado, e por vezes utilizando algumas manifestações culturais e tradicionais como meio de controlo político das massas.
\end{abstract}

Palavras-chave: Socialismo. Segunda República. Identidade. Tradição. Nacionalismo

\begin{abstract}
This article aims at analyzing the implementation of cultural policies in Mozambique from 1975 to 2009. Despite of many efforts, the results have been modest. The implementation of cultural policies has been subdivided in accordance with three generations or phases, namely the consolidation of identity and preservation of cultural heritage, the economic regulation of this sector and the production and diffusion of the cultural sector. The research was carried out through a qualitative approach, focused on a documental and legislative analysis of the available material, in accordance with a historical perspective. As a result, it is worth pointing out that during the socialist period the cultural policy expressed a vision rooted into a clear ideology (socialism); nevertheless, it did not consider adequately the cultural instances at the local level, whereas, with the "Second Republic", the State became less interventional and more regulator, leaving a great space to the market forces. In many cases, cultural and traditional manifestations have been used as a means for a political mass control.
\end{abstract}

Keywords: Socialism. Second Republic. Identity. Tradition. Nationalism.

\footnotetext{
${ }^{1}$ Recebido em: 13 Mai. 2020 | Aceito em: 21 Mai. 2020.

${ }^{2}$ Investigador no Centro de Estudos Internacionais do ISCTE-IUL, Lisboa; Professor Associado Visitante no Programa de Pós-Graduação e no Instituto de Estudos de África da Universidade Federal de Pernambuco; Professor no Mestrado em Cooperação e Desenvolvimento da Universidade Eduardo Mondlane, Moçambique. labronicus@gmail.com

${ }^{3}$ Músico e tenor, Professor de Canto no Curso de Música da Universidade Eduardo Mondlane, Moçambique. Mestre em Direitos Humanos, Desenvolvimento Econômico e Boa Governação, Universidade Técnica de Moçambique.
} 
A perspectiva mediante a qual a larga maioria dos estados africanos independentes abordou a questão do mosaico cultural e da identidade nacional em formação foi bem expressa por um cientista social daquele continente. Apesar de todas as distinções, por vezes subtis, por parte dos antropólogos, os políticos que acompanharam os países africanos para a fase pós-colonial tinham três objetivos fundamentais: independência, integração nacional, modernização (Skinner, 1998). E, dentro da modernização, desenvolvimento econômico acelerado. Tais objetivos foram alcançados em detrimento da complexidade cultural que caraterizava todos os países africanos, independentemente do fato de eles terem escolhido este ou aquele modelo de desenvolvimento (nomeadamente marxismo-leninismo, socialismo comunitário ou liberalismo). No geral, a maioria dos países africanos optou para soluções de matriz socialista, desaguadas muito cedo em regimes de partido único. Aqui, culturas e autoridades tradicionais estavam associadas ao obscurantismo, constituindo portanto obstáculos para o projeto de modernização que tinha sido perspectivado. Assim, juntamente com o poder político, o de tipo simbólico dos líderes tradicionais também diminuiu consideravelmente na transição do estado colonial para o pós-colonial (Awinsong, 2017). Líderes históricos, tais como Nyerere na Tanzânia ou Nkrumah no Gana entraram em conflito com as culturas locais. 0 pai do pan-africanismo, Nkrumah, por exemplo, mal conseguiu lidar com os Asantes no Gana, ao passo que na Nigéria também houve grandes dificuldades em integrar as chefias tradicionais nas novas formas de governação (Cappelen \& Sorens, 2018). Mesmo onde esta tentativa de integração entre socialismo comunitário de matriz africana e estruturas sociais e religiosas tradicionais foi levada a cabo, como no Senegal de Senghor, o resultado foi a continuação da dependência econômica em relação à antiga potência colonial, neste caso a França (Mazrui \& Wondji, 2010).

Os críticos mais radicais interpretam o falhanço das jovens nações africanas independentes através de fatores de continuidade com o colonialismo, principalmente do ponto de vista econômico, associados à cumplicidade das elites locais (Alemazungh, 2010), contribuindo à formação de um "colonialismo interno" que representa um dos marcos típicos da pós-colonialidade africana (Martins, 2019). A maneira como as políticas culturais, 
num dos países africanos mais pobres e de mais recente independência, Moçambique, procuraram quebrar (sem muito sucesso) os fatores coloniais ainda presentes no póscolonialismo constitui a reflexão central deste estudo.

Moçambique se insere no contexto do pós-colonialismo africano, com cerca de 15 anos de atraso em comparação com a maioria dos outros países africanos não só não fugiu à regra, mas, em consideração do seu programa de desenvolvimento acelerado e centralizado (Mosca, 2005), constituiu um dos países em que o conflito com culturas e autoridades tradicionais se mostrou mais duro.

É justamente de tais políticas culturais, que deviam acompanhar os mais importantes processos acelerados de desenvolvimento, planificados e implementados pela elite urbana da FRELIMO, que este artigo pretende falar, usando uma perspectiva histórica e ferramentas metodológicas típicas da pesquisa qualitativa, nomeadamente análise documental e legislativa.

Deve entender-se aqui com a expressão de "políticas culturais" o conjunto de princípios operacionais, práticas administrativas e orçamentárias e os procedimentos que fornecem uma base para a ação cultural do Estado, consoante a definição dada em 1967, durante a reunião da preparação da Conferência de Veneza da UNESCO.

Assim sendo, foram identificados três momentos de implementação das políticas culturais a nível nacional, em paralelo com as estratégias mais gerais de desenvolvimento econômico, e consoante as mudanças ideológicas do país. Tais etapas foram:

1. Consolidação da identidade e preservação do património (1975-1990);

2. Regulação econômica do setor cultural (1990-1997);

3. Produção e difusão do setor cultural (1997-2009). 
Duma forma resumida, é possível defender que, nas políticas da primeira geração, de 1975 a 1990 (data de aprovação de uma segunda Constituição, que introduziu a democracia e o multipartidarismo, marcando a transição para a "Segunda República"), a cultura serviu de instrumento político, complementando a edificação do homem novo. Se tratava do maior projeto de desenvolvimento humano lançado por Samora Machel, primeiro presidente de Moçambique, que visava formar cidadãos moçambicanos liberados do fardo colonial, assim como da cultura tradicional (Basílio, 2011). Por vários motivos, tais como a pobreza absoluta, luta armada e mau planejamento, os objetivos da construção de uma identidade única nacional resumida na figura do homem novo nunca se realizaram. Já nas políticas da segunda geração, de 1990 a 1997, o estado democrático mostra uma postura menos intervencionista, iniciando a legislar mais, e permitindo a ajuda externa e interna aos agentes da cultura. Nas políticas culturais da terceira geração, de 1997 a 2009, o Estado para além de continuar com a legislação cultural, elabora estratégias concretas para intervir no ramo da cultura. Mesmo assim, existem várias dificuldades na implementação das políticas culturais, pois a nível do governo ainda não existe um sistema nacional que possa organizar os recursos e as informações a partir de Maputo para as provinciais, os distritos, as cidades a as localidades. Por fim, nas zonas rurais e urbanas, as populações continuam a construir, produzir e criar valores e tradições de extrema importância para o país, sem recursos financeiros e registrando graves dificuldades quanto à difusão do seu trabalho e das suas produções artísticas.

\section{Consolidação da identidade e preservação do património (1975-1990)}

Sendo um país pertencente ao grupo Bantu, Moçambique abriga, dentro de suas fronteiras, uma variedade de tradições culturais. As suas fronteiras foram traçadas, em parte, por Portugal, com os objectivos de dividir comunidades unidas e aproximar grupos rivais (Landgraf, 2014, p.3). 
Desde o início do século 20 já se discutia a ideia de unidade nacional. Assim, várias organizações, de entre elas, a Liga Africana, o Grémio Africano, mais tarde Associação Africana da qual surgiu o Instituto Negrófilo, o Brado Africano, Associação dos naturais de Moçambique tinham interesse comum de lutar contra o racismo (Mateus \& Mateus, 2010).

Nas décadas de 1950 e 1960 já se fazia sentir o impacto do pan-africanismo por toda a África. Com o massacre de Mueda em 16 de Junho de 1960, várias acções foram levadas a cabo de modo a denunciar a opressão colonial. No campo da cultura, verificam-se algumas organizações nas cidades que visavam denunciar as atrocidades que os moçambicanos sofriam. Por exemplo: o Núcleo dos Estudantes Secundários de Moçambique, o Centro Associativo dos Negros da Colónia de Moçambique e o jornal 'A Tribuna', fundado em 06 de Outubro de 1962 (Chongo \& João, 2015: 12).

A literatura tinha a mesma função de denunciar todo o tipo de humilhações e brutalidades através dos poemas de Noémia de Sousa, José Craveirinha, Rui Nogar, entre outros. Nas regiões rurais, as resistências destacavam-se através das associações agrícolas, ou seja, camponeses que se organizavam com o objectivo de comercializar os seus produtos agrícolas, como é o caso da Sociedade Algodoeira e a Africana Voluntária de Moçambique. Repare-se que muito antes destas formas de resistência, já existiam tentativas que procuravam libertar o país da opressão colonial, ainda que tais grupos não tenham obtido resultados concretos, porque "durante muitas décadas de resistência, os nossos antepassados nunca lograram sucesso, porque cada grupo étnico ou regional lutava apenas para libertar a sua zona (Mabongo, 2015, p. 1)”.

Estes grupos étnicos eram baseados em diferentes usos e costumes, organizações militares, línguas comuns. Dos quais se destacavam:

"NYANJA (ocupando as margens do lago Niassa), MACUA (ocupando as províncias de Moçambique, parte da Zambézia, Niassa e Cabo Delgado), YAU (ocupando a maior parte do Niassa), MACONDE (na província de Cabo Delgado), SENA (na Zambézia, Manica e Sofala), NDAUNYAI-SHONA (Manica 
e Sofala), TSONGA-VATSUA-RONGA (maior parte da província de Gaza, Inhambane e Lourenço Marques) (Paredes, 2014, p. 141)”.

Quando os moçambicanos perceberam que tinham muitas diferenças entre eles e que lhes faltava uma consciência nacional, em 1962, na Tanzânia, formou-se a FRELIMO, que resultou da união de três movimentos: MANU (Mozambique African Nation Union), UDENAMO (União Democrática Nacional de Moçambique) e a UNAMO (União Africana de Moçambique), "com o objectivo de organizar, promover e proclamar a independência de Moçambique" (Barreto, 2010, p.205-206)". Mesmo com a formação da FRELIMO, a separação entre os grupos sociais de Moçambique ainda era evidente. 0 povo proveniente do norte do Rio Save acusava o do sul, de ser tribalista, já que este representava o maior número de pessoas no poder. Outra razão que causava falta de entendimento entre as regiões do norte e centro relacionava-se com o facto de as elites, os assimilados dos centros urbanos, regionais terem relações culturais mais próximas com as da Rodésia e do Malawi e os do sul com a cultura Sul-africana (Barreto, 2010). O objectivo era unir o povo contra um invasor comum. Assim, se cria a ideia de unidade nacional que, para ser concretizada, várias medidas seriam tomadas pela FRELIMO (Mabongo, 2015).

Um dos objectivos do segundo congresso da FRELIMO, que aconteceu em 1968, era acabar com as divisões dos diferentes grupos étnicos e transformar Moçambique em uma nação através da igualdade e o respeito pelas particularidades regionais (Mabongo, 2015). A cultura sempre mereceu destaque na política moçambicana. Já em 1966, havia sido criado o Departamento da Educação e Cultura e, em Junho 1975 do mesmo ano afirmou-se que a valorização da cultura seria a condição fundamental para a consolidação da unidade nacional e da identidade individual e de grupo (Omar \& Júnior, 2014). Logo depois da independência, implementa-se o Estado socialista com o objectivo de construir um homem novo. Uma das primeiras tentativas da intervenção do Estado na cultura foi a organização das populações rurais através de aldeias comunais (Landgraf, 2014). 
Inlia (2016) afirma que as aldeias comunais foram criadas para inspirar o espírito de cooperação entre as comunidades, de criação de recursos com base na agricultura e aplicar a ideologia política do partido. Porém, o seu desenvolvimento foi lento; os camponeses desconfiavam das novas formas, preferindo o esquema usual da agricultura de família e/ou de subsistência. As aldeias comunais tinham como objectivo "mostrar os mecanismos socialistas usados para a organização da força nas zonas rurais para que se estruturassem em uma nova sociedade revolucionária" (Maloa, 2016, p. 70).

As aldeias comunais encontraram resistência por parte dos camponeses uma vez que se viam forçados a mudar a sua força de trabalho que era dedicada e controlada tradicionalmente pela sua linhagem para se unir a grandes aglomerados de famílias, bem como pela dependência aos chefes das aldeias para poder ter acesso às terras. As aldeias comunais representaram uma violência cultural porque vários camponeses voltaram às suas antigas residências, em parte pela insatisfação dos seus chefes tradicionais já destituídos das suas funções pelos funcionários do partido, assim como começavam a fracassar (Inlia, 2016).

Se por um lado se afirmava que se reconhecia o peso da importância das tradições nas vidas das pessoas, por outro lado se combatia de várias formas e seleccionava-se apenas os valores ligados à modernidade, assim as práticas como o alcoolismo, a poligamia, o lobolo, o curandeirismo eram vistas como contrárias ao espírito do progresso. 0 novo projecto de sociedade devia estar de acordo com os novos sistemas de produção, de solidariedade e das artes, escolhidas e controladas pelo governo.

As práticas próprias do universo sócio cultural moçambicano rotuladas de obscurantismo foram combatidas e por conseguinte, da cultura local, ficou aquilo que os antropólogos classificam de folclore, como por exemplo, danças para a recepção de dignitários em visita ao País ou para festivais (Mabongo, 2014, p. 40). 
A revolução custou a liberdade e as atividades duma das organizações mais antigas de África. Os líderes tradicionais foram banidos, pois eram associados aos dois inimigos da revolução: a tradição e a administração colonial. Com efeito, durante a luta de libertação, a Frelimo e os líderes tradicionais tiveram um relacionamento conflituoso sobre a gestão social e económica nas zonas libertadas. Este conflito foi interpretado pela Frelimo como resultado de diferenças ideológicas entre a ala revolucionária e os líderes tradicionais que queriam fazer da liberdade, oportunidade para enriquecimento próprio a custa do povo.

Uma vez que o inimigo era identificado com o sistema opressor, os líderes tradicionais, a menos que provassem a sua desvinculação com o poder linhageiro e as práticas coloniais, passaram também a ser considerados inimigo; um "inimigo interno" de natureza ideológica cujo combate era decisivo para a construção do Homem Novo (Mabongo, 2014, p. 40).

Nas zonas urbanas, três medidas foram tomadas: a nacionalização dos imóveis, a instalação de grupos dinamizadores para difusão da linha do partido na tentativa de implementar o sentimento de identidade e memória nacional imaginária através de danças, ritmos musicais, esculturas Macondes, registos de residências (Landgraf, 2014).

Com a proclamação da independência em 1975, a cultura mereceu atenção por parte do Estado. Foi, assim, criado o Ministério da Educação e Cultura, que tinha algumas instituições sob sua tutela, nomeadamente: Instituto Nacional da Cultura, Serviço Nacional de Bibliotecas, Serviço Nacional de Rádio Educativa, Biblioteca Nacional de Moçambique. Ainda em 1975, foi criada a Direcção nacional de Cultura, que, mais tarde, acabou criando o Centro de Estudos Culturais. Com a realização da reunião Nacional de Cultura em 1977, recuperou-se alguns prédios como, por exemplo, a ex-casa Goa, para além de dirigir programas de intercâmbio cultural e formar grupos em várias linguagens artísticas.

Com vista à valorização e preservação do património histórico e identitário do país, foi realizada em 1978, a 1a Reunião Nacional de Museus e Antiguidades, na Ilha de Moçambique (...). A reunião possibilitou a avaliação 
da capacidade de ingerência do Estado e do engajamento da população em projectos de valorização, preservação e democratização das actividades culturais. A tentativa era implantar a planificação do funcionamento museal, contando com as orientações pelo Departamento de Trabalho Ideológico do Partido (DTIP) (Borges, 2001, p. 243).

A intervenção no campo das artes foi reforçada em 1977 com a criação do Centro de Estudos Culturais e das Casas de Cultura gerenciados pelo Ministério da Cultura, cujas funções eram de ministrar cursos de linguagens artísticas e difundir as culturas nacionais nos bairros, aldeias e distritos. Afirmava-se que os círculos culturais deveriam ser independentes para o desenvolvimento espontâneo da cultura. A cultura tradicional, de elite, de massa, não era aceitável, apenas as manifestações que valorizassem o homem novo e a nova sociedade (Landgraf, 2014).

Em Dezembro de 1983, com Decreto Presidencial n. 84, criou-se a Secretaria de Estado da Cultura, que, para além de ser dirigida por um Secretário de Estado, estava subordinada ao Conselho de Ministros. Nesse sentido, a Cultura deixou de ser parte de um Ministério e passou a ser incorporada numa Secretaria, prestando contas ao Conselho de Ministros.

Mantêm-se a preocupação com a criação de instituições científicas e técnicas (museus, bibliotecas, arquivos, etc.) necessárias à protecção e valorização do património cultural, e surge a atenção para a produção de bens culturais (obras de cinema, artes plásticas, música, dança, etc.) de forma ainda tímida, para sua comercialização. Portanto o início das políticas de segunda geração, da regulação da dimensão económica das actividades artístico-culturais, ocorre no momento de aproximação com o bloco capitalista (Omar \& Júnior, 2014, p. 7).

Um dos objetivos do primeiro governo de Moçambique era o controlo de todas atividades culturais, com

criação de comissões para colecta e estudos de todas as manifestações culturais do país, baseando-se na vida do povo e em hábitos culturais; 
experiências na medicina tradicional; guerras tribais; guerra de resistência à penetração estrangeira; períodos antes, durante e depois do colonialismo português; experiências na luta clandestina, na Luta Armada de Libertação Nacional e experiências que iam sendo adquiridas. Anos subsequentes, foram caracterizados pelas contínuas campanhas de colecta, registo de vários aspectos da cultura e tradições locais, por formações de órgãos de gestão do mesmo património e leis visando a sua protecção legal (Omar \& Júnior, 2014, p. 6).

O ARPAC, ligado ao Ministério da Cultura, foi criado em 1983 para assegurar o destino dos documentos recolhidos durante a Campanha Nacional de Preservação e Valorização da Cultura, que tiveram lugar entre os anos de 1978 a 1982. Este trabalho foi feito, em todo o país, por quadros moçambicanos e estrangeiros, entre eles, professores. 0 registo era feito de forma manuscrita e guardado pelo Arquivo do Património Cultural (Pehrsson, 2001). Contudo, o material recolhido ainda não foi divulgado e, em outros casos, não se sabe onde se encontra. Note-se também que os bens colectados no período da campanha nacional de preservação do património em Moçambique não se encontram no Museu da Ilha de Moçambique, declarado Património Mundial da Humanidade. Em contrapartida, o que se pode encontrar na Ilha, são relíquias daqueles que dominaram o país (Omar \& Júnior, 2014).

Em 1983, o Estado moçambicano assinou um acordo com a PNUD, de modo a implementar o projecto MOZ/82/2004, cujo objectivo era de contribuir na preservação do Património Cultural da República Popular de Moçambique. Deste modo, foi criado o Arquivo do Património Cultural. Em 1984, Moçambique recebe o apoio do Governo da França através do Antropólogo Michael Samuel, para formar profissionais em matérias de investigação histórica, antropológica e sociológica (Omar \& Júnior, 2014).

Se nos primeiros anos da independência não havia leis sobre a cultura e as acções do Estado estavam viradas à construção de uma nova sociedade, a partir de 1980 o governo mostrouse preocupado com a grande pobreza do país. 
Em 1979, foi aprovado o Plano Prospectivo Indicativo (PPI) para o período 1980-1990. O mesmo era definido como guia de acção e instrumento fundamental para a construção de uma economia socialista relativamente desenvolvida. Para tal foram defendidos três eixos centrais: (i) a socialização do campo e o desenvolvimento agrário; (ii) a industrialização; e (iii) a formação e qualificação da força de trabalho (João \& Chongo, 2015, p. 30).

Este plano viria a fracassar, pois mesmo antes de se terminar a organização e sistematização da estratégia de construção e do plano de reconstrução nacional, uma guerra civil protagonizada pela RENAMO (Resistência Nacional de Moçambique) iniciou, concluindo-se apenas em 1992, com o cordo Gerais de Paz de Roma. 0 regime minoritário da Rodésia do Sul de Ian Smith (até 1981, data dos acordos de Lancaster House e da transformação da Rodésia em Zimbabué, tradicional aliado de Moçambique) e, depois, do regime do apartheid da África do Sul, apoiaram esta prolongada ação de desestabilização que, diferentemente da narrativa oficial propalada pela FRELIMO, tinha bases sólidas justamente naquela camada de pequenos e médios camponeses que o regime socialista não conseguiu convencer, com as suas propostas consideradas hostis de políticas econômicas e de desenvolvimento. Diante destes acontecimentos, Moçambique teve que desviar parte dos recursos para poder enfrentar a guerra civil (Inlia, 2016).

Em 1984 foi assinado o Acordo de Nkomati, um acordo de não-agressão e boa vizinhança com a África do Sul, que se tornou necessário em razão da situação extremamente crítica que o país estava atravessando, diante dos ataques da RENAMO e das ações por vezes diretas (sobretudo em Maputo e província) do governo sul-africano, a caça dos muitos membros do ANC (African National Congress) refugiados em Moçambique. Tais indivíduos tiveram de deixar o solo moçambicano, consoante os Acordos de Nkomati, com grande perplexidade não apenas do ANC, mas de larga parte da esquerda internacional. Ainda em 1984 Moçambique é aceite como membro do Fundo Monetário Internacional e do Banco Mundial, o que permitiu ao país de começar a receber uma significativa assistência bilateral das instituições internacionais de ajuda ao desenvolvimento (Inlia, 2016). A "viragem" rumo a uma economia liberal já tinha iniciado, portanto, durante a governação de 
Samora Machel (que faleceu em 1986), que tinha compreendido o fracasso de um modelo de desenvolvimento baseado em ideais iluministas e socialistas, mas que percebia com graves dificuldades o mundo cultural mais profundo do país, acima de tudo o universo camponês e, em segundo lugar, tudo quilo que dizia respeito aos valores tradicionais e religiosos.

Foram, entretanto, tomadas várias medidas de modo a superar a crise, segundo uma linha "que promovia as condições de transição para a economia de mercado e a democracia" dentro de um "contexto de guerra civil, de pressão e de globalização" (Feliciano, 1998, p. 3).

A abertura do país para a economia liberal trouxe benefícios aparentes não só a nível da agricultura, mas a vários setores como, por exemplo, a cultura, através de significativos apoios, a partir de 1987. Este apoio começou em forma de projectos, com financiamentos pontuais que gradualmente se transformaram em um programa institucional ligado ao Ministério da Cultura. 0 primeiro grupo a receber apoio foi o grupo de teatro Mutumbela Gogo, através do palco do Teatro Avenida, na capital Maputo. Mais tarde, começou um projeto de irmandade entre os municípios do Gotemburgo e da Beira, em que a principal linha de encontro entre as duas cidades era a cooperação das Casas de Cultura dos dois países (Pehrsson, 2001).

No mesmo ano, recebeu-se apoio para o Departamento de Museus do Ministério da Cultura, para o Departamento de Monumentos, para o Arquivo do Património Cultural e sobretudo para o Ministério da Cultura. Para além destas instituições, em 1992, quatro das Casas de Cultura do país começaram a receber apoio financeiro. Durante os anos 90, três associações, nomeadamente, o Núcleo de Arte, Associação dos Escritores Moçambicanos e a Associação dos Músicos Moçambicanos, tiveram apoio financeiro através do Fundo para o Desenvolvimento Artístico Cultural canalizado pela Embaixada da Suécia que dispunha de um pequeno fundo para ajudar os projetos pontuais (Pehrsson, 2001).

Foi aprovada, pela Assembleia da República Popular de Moçambique, a Lei n. ${ }^{\circ} 10 / 88$ de 22 de Dezembro, que determina a protecção legal dos bens materiais e imateriais do povo moçambicano. Esta Lei foi a primeira do género no país independente, que surgiu da 
revogação do diploma legislativo n.o 825, de 20 de Fevereiro de 1943, criado no período colonial, que tinha como objetivo proteger e salvaguardar o património da presença colonial portuguesa, em Moçambique. A aprovação da legislação de protecção do património cultural moçambicano após a independência baseou-se nos princípios fundamentais da responsabilidade do Estado na promoção do desenvolvimento da cultura, acção, essa, que passou pela identificação, registo, preservação e valorização dos bens materiais e imateriais, onde está inserida a memória do povo moçambicano. A protecção deste património assegura a transmissão às gerações presentes e futuras do legado arqueológico, histórico, cultural e artístico, dos nossos antepassados, assim como das suas conquistas e dos valores contemporâneos da cultura moçambicana (Lei 10/88, de 22 de Dezembro: 14).

Com a aprovação da Lei n.- 10/88 foram lançadas as bases para a protecção do património cultural moçambicano e para o desenvolvimento dos processos da sua inventariação, classificação e conservação. Segundo Rubim (2007), as políticas culturais depois de 1992 foram elaboradas de modo a formar-se um sistema cultural dividido em um conjunto de 7 momentos que dinamizariam a vida cultural do país, que são: 1) Criação, invenção e inovação; 2) Difusão, divulgação e transmissão; 3) Circulação, intercâmbios, trocas, cooperação; 4) Análise, crítica, estudo, investigação, pesquisa e reflexão; 5) Fruição, consumo e públicos; 6) Conservação e preservação; 7) Organização.

Estes momentos são divididos em dois grupos, os de fortalecimento: 1, 2, e 5, em especial para o mercado, invenção e inovação, divulgação e consumo. Outros momentos estão ligados a intercâmbios, análise, conservação e organização e dependem dos órgãos e instituições do Estado. Como explica Pehrsson,

Como o objectivo é promover a cultura como um factor de desenvolvimento económico, social e humano em Moçambique como forma de dar resposta à emergência global da nova economia criativa que gera milhões de empregos no turismo cultural, musica, teatro, dança, artesanato e artes plásticas nas indústrias criativas, e, ao mesmo tempo, dar resposta à ansiedade da 
sociedade moçambicana em perceber até que ponto o sector da cultura contribui no PIB - Produto Interno Bruto (Pehrsson, 2001, p. 66).

A lei n. ${ }^{o}$ 10/88, para além da protecção do património nacional, visava colocar os bem nacionais no plano do reconhecimento internacional, por exemplo, em 1991, a Ilha de Moçambique foi inscrita na UNESCO para concorrer à categoria de Património Mundial. Segundo o Documento n⿳o. SC-91/CONF.002/15, na Sessão número 15, da Comissão do Património Mundial da UNESCO, que decorreu de 09 a 13 de Dezembro de 1991, em Cartago, cidade da Tunísia, a Ilha de Moçambique foi integrada na lista do património mundial. 0 valor universal da Ilha foi reconhecido segundo dois critérios da Convenção da UNESCO:

A cidade e as fortificações na Ilha de Moçambique, e na Ilha de São Lourenço, constituem um exemplo extraordinário de uma arquitectura em que as tradições locais, as influências portuguesas e, em menor grau, as influências indianas e árabes estão todas entrelaçadas. A Ilha de Moçambique constitui um testemunho importante do estabelecimento e do desenvolvimento das rotas marítimas portuguesas entre a Europa Ocidental e o Sub-continente indiano e, por consequência, toda a Ásia (Gonçalves, Lopes \& Rossa, 2018, p.141).

O reconhecimento da Ilha de Moçambique como património da UNESCO representa o ato que assinala a transição entre a primeira e a segunda fase, com mudanças ideológicas, econômicas e políticas radicais, que refletir-se-ão nas políticas culturais implementadas pelo governo.

\section{Regulação econômica do setor cultural (1990-1997)}

A aproximação ao modelo ocidental de economia teve repercussões diretas nas políticas culturais, com a aprovação de medidas típicas de um Estado regulador de um 
mercado cada vez mais complexo e fora do controlo, sobretudo em consideração dos meios muito modestos a disposição das autoridades locais, em associação com os crescentes níveis de corrupção em todos os setores da vida do país, cultura e arte inclusas.

Já em pleno socialismo Moçambique tinha aprovado uma primeira lei a respeito da comercialização e exportação dos bens culturais, tais como obras, marfim, peles de fauna bravia, mobílias, esculturas, pedras preciosas e semipreciosas. Se tratava do Decreto 10/81 de 25 de Junho, aprovado com o objetivo de evitar o empobrecimento do património cultural, garantindo que não houvesse desvios de importantes fontes de receitas para a economia nacional.

Sete anos mais tarde outra medida econômica viria a ser aprovada. Com efeito, o Decreto no 10/88 de 9 de Agosto Aprova o Regulamento do Espectáculo, que dentre várias disposições visava "Proceder ao licenciamento de empresários e promotores de espectáculos; definir critérios para se proceder a fixação de preços e taxas de arrendamento de recintos de espectáculos e aluguer de equipamentos de som, luz e outros" (Min. Educ. e Cult., 2017, p. 55).

Em 1990, mais um decreto ligado ao setor econômico, o Diploma Ministerial no 88/90 de 3 de Outubro estabelecia regras de importação e aluguer de vídeos cassetes gravadas. Este Diploma visava impor medidas contra a pirataria, afirmando que quem importasse vídeos cassetes gravadas deveria exibir a comprovação da posse dos direitos de exibição, confirmada pelo Instituto Nacional de Cinema (Min. Educ. e Cult., 2017).

Mesmo com estes esforços do Governo, a regulamentação econômica encontrou um terreno impróprio para a sua implementação, com falta de equipamentos e órgãos culturais, assim como de uma efetiva vontade de proteger o património artístico e cultural. Assim, de 1992 a 1996, várias medidas foram criadas de modo a fechar esta lacuna, segundo afirma Landgraf (2014, p.17). 
Nestes quatro anos, entre Decretos ${ }^{4}$ (deliberados essencialmente pelo Conselho de Ministros), Diplomas Ministeriais ${ }^{5}$ (deliberados pelos Ministério), e Leis ${ }^{6}$ foram aprovadas normatizações nas seguintes áreas (Moçambique, 2007): i) Patrimônio - com a normatização de instituições sobre Patrimônio Cultural, Patrimônio Arqueológico e Museu de Etnologia; ii) Formação e pesquisa - em música, dança, artes visuais, canto e na criação de um órgão regulamentador das bibliotecas; e iii) Mercado cultural - com regras sobre audiovisual e a Lei do Mecenato.

A aprovação da legislação de proteção do património cultural moçambicano após a independência baseou-se no princípio fundamental da responsabilidade do Estado na promoção do desenvolvimento da cultura. Um tal processo devia passar pela identificação, registo, preservação e valorização dos bens materiais e imateriais, onde está inserida a memória do povo moçambicano. A ideia era de que a proteção deste património ia assegurar a transmissão às gerações presentes e futuras do legado arqueológico, histórico, cultural e artístico dos antepassados, assim como das suas conquistas e dos valores contemporâneos da cultura moçambicana (Min. Educ. e Cult., 2017)

${ }^{4}$ Decreto no 4/91 de 3 de Abril - Estatuto Orgânico do Instituto Nacional do Livro e Disco; Decreto no 26/93 de 16 de Novembro Cria o ARPAC - Arquivo do Património Cultural; Decreto no 27/94 de 20 de Julho - Aprova o Regulamento de Protecção do Património Arqueológico e a composição do Conselho Nacional do Património Cultural; Decreto no 19/96 de 11 de Junho - Cria o Museu Nacional de Etnologia; Decreto no 20/96 de 11 de Junho Cria o Museu Nacional de Arte Decreto no 38/96 de 20 de Agosto - Cria a Companhia Nacional de Canto e Dança.

${ }^{5}$ Diploma Ministerial no 39/91 de 8 de Maio - Cria na cidade de Maputo a Escola Nacional de Música, também designada abreviadamente por Escola de Música; Diploma Ministerial no $\mathbf{0}$ /91 de 15 de Maio - Cria, na cidade de Maputo a Escola Nacional de Dança - Publica o Estatuto Orgânico da Escola Nacional de Dança, o Regulamento das Carreiras Profissionais e o Quadro do Pessoal; Diploma Ministerial no 43/91 de 22 de Maio Cria, na cidade de Maputo a Escola de Artes Visuais - E.A.V. - Publica o Estatuto Orgânico da Escola de Artes Visuais, o Regulamento das Carreiras Profissionais e o Quadro do Pessoal - Diploma Ministerial no 103/92 de 22 de Julho

Estatuto Orgânico da Biblioteca Nacional de Moçambique.

${ }^{6}$ Lei no 10/88 de 22 de Dezembro - Determina a protecção legal dos bens materiais e imateriais do património cultural moçambicano; Lei no 4/94 de 13 de Setembro - Lei que estabelece os princípios básicos que permitem estender a acção das pessoas jurídicas, singulares ou colectivas, públicas ou privadas, que desenvolvem actividades, ou, financeiras e materialmente as apoiem, no campo das artes, letras, ciência, cultura e acção social; Lei no 4/2001 de 27 de Fevereiro - Aprova os Direitos de Autor e revoga o Código dos Direitos de Autor aprovado pelo Decreto-Lei no 46.980, de 27 de Abril de 1966 
Havendo necessidade de aprovar o Regulamento do Património Arqueológico para pôr em funcionamento o Conselho Nacional do Património Cultural, o Conselho de Ministros, ao abrigo do artigo 27 da Lei n.. 10/88, de 22 de Dezembro, aprovou o Decreto no 27/94 de 20 de Julho. Trata-se de um conjunto de regras finalizadas a licenciar os trabalhos e os registos arqueológicos em Moçambique, bem como garantir a preservação de todo o património arqueológico.

A regulamentação econômica, neste período, culmina com a Lei n.. 4/94 de 13 de Setembro (Lei do Mecenato), que visava proteger e financiar a criação artística, desportiva, educacional e social através de benefícios fiscais concedidos às pessoas jurídicas. Os destinatários desta lei são as associações e fundações que prosseguem as suas actividades sem fins lucrativos, ou seja, associações constituídas nos termos da Lei n.․ 8/91, a Lei das Associações. Segundo esta lei, vários são os benefícios para as empresas que praticam doações: seu Imposto sobre Rendimentos de Pessoas Colectivas é reduzido, têm incentivos sociais tais como publicidades sem custos, obtenção de diplomas de honra que constituem vantagem durante as contratações públicas dos serviços privados. No entanto a aplicação desta lei se tornou em larga medida questionável, pois ainda não há um órgão estatal que garanta a sua operacionalização (Langraf, 2014).

Desta forma, já havia como implementar as normas de regulação econômica, faltando porém políticas e estratégias culturais melhor definidas.

\section{Produção e difusão do setor cultural (1997-2009)}

Para Sousa (2010: 138-139), compete ao Estado sustentar a cultura, regular a produção e disponibilizar meios da sua difusão para toda a população. Para isso torna-se importante haver projetos de unificação cultural suficientemente ambiciosos tais que possam abarcar todas as diversidades locais. Tais projetos só serão eficazes se estiverem 
incorporados dentro da política cultural, ou seja, no interior de um plano estratégico que possa funcionar a nível das instituições e na sociedade, no geral.

Foi através destes objetivos que o Governo criou o Política Cultural de Moçambique e a Estratégia de sua Implementação, colocando como prioridades da sua acção cultural "a pesquisa sociocultural, a preservação e divulgação do património cultural, a criação e interpretação artísticas; as associações de interesse cultural; a formação artística e profissional; a participação da comunidade; o desenvolvimento de redes de instituições culturais; a cooperação e intercâmbio internacionais"; que deveriam se realizar através de acções concretas tais como:

Promover o desenvolvimento da cultura e personalidade moçambicanas e garantir a livre expressão dos valores nacionais (...); Promover a difusão da cultura moçambicana, no plano nacional e internacional, e desenvolver acções com vista a fazer beneficiar o povo moçambicano das conquistas culturais de outros povos; Promover o respeito, a valorização e a aceitação das manifestações culturais de cada comunidade; Promover a identificação, preservação e valorização do património cultural e artístico nacional (Min. Educ. e Cult., 2017, p. 40 - 41).

A política cultural moçambicana orienta-se pela ideia de democratização da cultura, na qual se constrói todos os seus princípios e as formas de implementação. Ao afirmar que "todos os cidadãos têm igual direito de participação na vida cultural e de acesso à fruição dos benefícios da cultura e arte", entre os seus objectivos, compromete-se, no que se refere à cultura, em criar ações para promover e difundir tudo que estiver ligado à cultura moçambicana, quer no plano nacional, quer no plano internacional. Isto significa desenvolver ações com vista a trazer benefícios ao povo moçambicano através das conquistas culturais de outros povos, apoiando todas as ações que possam promover a igualdade de acesso e de participação dos cidadãos à Cultura e às Artes moçambicanas.

É possível ver nesta política a afirmação do valor da cultura e a necessidade da criação de condições para uma maior participação criativa, livre e democrática de cada um e 
da sociedade civil no seu conjunto, assim como o respeito pela diversidade de confissões religiosas e de origens étnicas. Tais condições seriam encontradas nos direitos culturais que são garantidos, em primeiro lugar pela Constituição da República de 2004, que no seu preâmbulo, já os descreve de forma clara quando refere que:

A presente Constituição reafirma, desenvolve e aprofunda os princípios fundamentais do Estado moçambicano, consagra o carácter soberano do Estado de Direito Democrático, baseado no pluralismo de expressão, organização partidária e no respeito e garantia dos direitos e liberdades fundamentais dos cidadãos" (Moçambique, 2004).

O pluralismo de expressão é a base para a defesa dos direitos culturais: o artigo 3 garante o Estado de Direito, o pluralismo de expressão, mesmo de tipo político, assim como o respeito dos direitos e liberdades fundamentais do homem. Princípios, esses, reforçados pelo art. 48.

Finalmente, no artigo 12 o Estado concede a liberdade às diferentes organizações religiosas para praticar as suas atividades, em conformidade com as leis vigentes no país.

Desta forma, o Estado reconhece o direito das pessoas de manifestarem as suas opiniões e sentimentos sem medo, sempre para o bem comum. Por exemplo:

Quando os jornalistas têm o direito de acesso às fontes de informação, têm a possibilidade de exprimir livremente as suas opiniões e os jornais podem publicá-las livremente etc. cria-se uma base para o pluralismo de opiniões que é impertinente para uma sociedade democrática. (António, 2007, p. 19).

Em paralelo à Política Cultural de Moçambique e Estratégia de sua Implementação (1997), foram aprovados decretos ${ }^{7}$, leis e diplomas ministeriais, embora a maioria deles

\footnotetext{
${ }^{7}$ Decreto no 29/98 de 9 de Junho - Determina a protecção legal dos bens materiais e imateriais do património cultural moçambicano, Decreto no 41/2000 de 31 de Outubro - Cria o Instituto Nacional do Audiovisual e Cinema, Decreto no 927/2001 de 4 de Setembro - Regulamento de aposição obrigatória do Selo nos
} 
ligados à proteção dos bens culturais, visando uma difusão cultural organizada e fiscalizada. Destas leis uma maior atenção foi direcionada aos direitos autorais e conexos, como demonstram a Lei no 4/2001 de 27 de Fevereiro - Aprova os Direitos de Autor e revoga o Código dos Direitos de Autor aprovado pelo Decreto -, a Lei no 46.980, de 27 de Abril de 1996; do Decreto número 927/2001 de 4 de Setembro - Regulamento de aposição obrigatória do Selo nos Fonogramas; e Diploma Ministerial no 8/2003 de 15 de Janeiro Estabelece regras para a operacionalização e exequibilidade do Regulamento de Aposição Obrigatória de Selo nos Fonogramas, nos termos do artigo 3 do Decreto no 27 /2001, de 4 de Setembro.

A Lei dos Direitos do Autor e Conexos visa proteger, por um lado, as obras científicas, literárias e artísticas, bem como os intérpretes, os operadores de rádio, os produtores de fonogramas e dos executantes. Para tal é necessário que haja uma pessoa ou grupo de pessoas que criam a obra, por originalidade ou conexão (Min. Educ. e Cult., 2017).

Aliado a estas mediadas, foi aprovado o Decreto n.o 38/2016, de 31 de Agosto Código de Publicidade, que revoga o Decreto n.ำ 65/2004, de 31 Dezembro. Abdalla \& Murrure (2016, p. 70) sintetizam a o Código de Publicidade da seguinte maneira:

Em todo o procedimento que vai desde a contratação de serviços, de que o anunciante faz às agências de publicidade, até à fase do recebimento do anúncio, por parte do destinatário, os direitos de autor devem ser observados; os actos praticados pelos cantores, atores, intérpretes, modelos, figurantes, consubstanciam um labor de cariz intelectual cuja tutela não deve escapar aos ditames da propriedade intelectual (...); proibição expressa do plágio ou imitação.

O Decreto-Lei n. 35/2006 de 6 de Setembro aprova a criação e Funcionamento da Polícia Municipal, com tarefas de fiscalização do cumprimento do Regulamento de Aposição

Fonogramas, Decreto no 25/2002 de 22 de Outubro - Altera a designação do ARPAC, Decreto no 31/2004 de 18 de Agosto - Cria o Museu da Ilha de Moçambique, Decreto no 53/2004 de 1 de Dezembro - Cria as Casas Provinciais de Cultura, abreviadamente designadas por CPC e aprova o seu Estatuto-Tipo, Decreto no 1/2005 de 23 de Fevereiro - Cria o Museu de Chai, Decreto no 46/2007 de 1 de Dezembro - Cria as Bibliotecas públicas provinciais 
Obrigatória de Selo nos Fonogramas. No caso da Polícia Municipal encontrar produtos pirateados deveria entrega-los à Polícia da República de Moçambique. Por mais que seja uma leis de fiscalização, esta medida visava reforçar também o sector da divulgação, na medida em que incentiva os produtores culturais a produzir e vender os seus produtos culturais, sem temer perdas para a pirataria.

Para se entender melhor o que os direitos culturais significam para os nossos dias, é interessante analisar o discurso do então presidente da República de Moçambique, Armando Emílio Guebuza proferido em 2008, no Festival Nacional de Cultura, na província de Gaza. Nas suas primeiras linhas refere que a cultura é uma das formas do reconhecimento das diversas modalidades de ser dos moçambicanos, bem como a garantia da unidade nacional. Afirma-se aqui a ideia de uma única nação, objetivo dos primeiros anos da independência: "Cultura Moçambicana: fonte da nossa auto-estima, da consolidação da Unidade Nacional e da promoção do nosso bem-estar (Moçambique, 2008)". Uma atenção aos processos identitários e à valorização do que é "orgulhosamente moçambicano" deu-se sobretudo ao longo da governação de Armando Emílio Guebuza (2004 - 2014), não sem o recurso a uma retórica nacionalista vazia.

Guebuza afirma que é necessário que todas as pessoas e grupos possam reconhecer e dar expressão à sua identidade cultural, ao partilharem uma visão comum, pois é pela diversidade que se chega à unidade nacional. Afirma ainda que essa diversidade deve-se apresentar como cultura na sua plenitude e não através de expressões ou manifestações artificialmente isoladas, umas das outras, assim, o que se pretende é o sentimento de se ter raízes que se mantêm firmes (Moçambique, 2008).

Diferentemente da época socialista, porém, estas declarações tornam claro o fato de que a cultura tem também uma dimensão individual pois é "através da cultura, que se pode conhecer melhor e se perceber a pessoa humana, uma das condições vitais na escolha acertada de opções e políticas de desenvolvimento." (Moçambique, 2008). É a partir do indivíduo que o governo traça as suas políticas culturais, pelo que, a ação governativa surge pela necessidade do "desenvolvimento da cultura como componente determinante da nossa 
personalidade identitária, da Unidade Nacional, da coesão e da harmonia entre os moçambicanos, as instituições e o projecto de desenvolvimento social e económico da Nação Moçambicana". Este destaque vai ajudar, segundo Guebuza, também para resolver o maior problema que o país enfrenta, a pobreza; por isso a cultura está na Agenda Nacional de Luta contra a Pobreza (Lopes, 2016).

As políticas culturais em Moçambique ainda são determinadas por constrangimentos financeiros. Os recursos são limitados, forçando o Estado a preferir programas populares, aqueles cujos resultados são imediatos, como os festivais, sobretudo e canto e dança. No seio das políticas culturais, da responsabilidade do Ministério da Cultura e Turismo criou-se o Fundo para o Desenvolvimento Artístico e Cultural, uma instituição que depende das verbas do Governo para captação fonográfica, pesquisas e viagens culturais, edição de livros. Porém é uma instituição ainda pequena, considerando que só existe em Maputo e sem representação em nenhuma outra província (Lopes, 2016).

Apesar das dificuldades que a cultura enfrenta, Nassabe \& Mandlate (2011), no seu relatório para o Instituto Nacional de Estatística, intitulado Estatística da Cultura, observaram que a actividade cultural tem tido continuidade, como mostram os seguintes dados:

a) Grupos culturais: o número de grupos culturais registados no país em 2009 foi de 1 535, sendo 50\% de grupos culturais que se dedicavam a dança, seguindo a música com $25 \%, 16 \%$ grupos corais e teatro com $9 \%$.

b) Festivais de cultura: nos vários festivais de cultura de 2007 a 2009 houve uma oscilação no número de participantes em 2007, foram registados 12 028, 13700 em 2008 e 10487 em 2009.

c) Promotores culturais: os 416 promotores de eventos culturais só tinham alvará de promoção de eventos culturais a nível de província 53\%, a nível nacional 45\% e 1\% a nível distrital. 
d) Casas de cultura: em 2009 existiam 18 casas da cultura, destas 7 se localizavam na Província da Zambézia, das quais 6 se encontravam nos distritos e uma na Cidade de Quelimane. Não houve registo de casas de cultura em Tete, Manica e Maputo Província, o que representa ainda um número é muito reduzido

e) Artistas plásticos: em 2009 foram registados 82 artistas plásticos, dos quais 28 na província da Zambézia, 13 em Nampula e 12 na Cidade de Maputo.

f) Salas de cinema e teatro: de 2007 a 2011 verificou-se uma diminuição do número de espectadores nas salas de cinema em cerca de 72\%. Sendo as províncias de Sofala e de Zambézia as tiveram maior diminuição dos espectadores. Enquanto que em todos anos Maputo Cidade é a província que registado maior número de espectadores nas salas de cinema em relação a outras províncias. Foram exibidas 2963 sessões exibidas nas diversas salas de cinema, sendo $89 \%$ foram sessões de filmes, $8 \%$ de teatro e $3 \%$ de outras actividades.

\section{Reflexões conclusivas}

O Estado moçambicano mudou radicalmente a sua postura em relação às políticas culturais, passando de autor, disseminador e controlador da cultura, para legislador e facilitador das acções culturais no país. Tal mudança é filha da evolução políticoinstitucional de Moçambique, na sua transição do socialismo ao modelo liberal ocidental. As ações do governo de 1975 a 1990 eram voltadas para uma ideia de cultura como instrumento político, de modo a construir um homem novo. Por vários motivos acima recordados, tais objetivos nunca se realizaram.

Já nas políticas da segunda geração, de 1990 a 1997, o Estado se torna democrático, tendo um papel menos intervencionista e mais legislador, criando várias leis e permitindo a ajuda externa e interna aos agentes da cultura. Nesta fase é evidente a atividade legislativa do governo (muito menos do parlamento), por vezes até excessiva, assim como claramente 
observável é a dificuldade em fiscalizar o que tinha sido legiferado. Uma confirmação, esta, de como esta fase da vida pública moçambicana esteja estritamente relacionada com os anseios dos doadores ocidentais, por detrás dos quais está, em larga medida, a filosofia que inspira as novas leis, por vezes desligada do contexto local.

Finalmente, nas políticas culturais da terceira geração, de 1997 a 2009, o Estado para além de continuar com a legislação cultural, elabora estratégias concretas para intervir no ramo da cultura. A figura do presidente Guebuza, aqui, é incontornável, positiva e negativamente, para a evolução das políticas culturais em Moçambique. Com efeito, se por um lado Guebuza promove as peculiaridades artísticas locais, por outro as utiliza como controlo das massas (juntamente com o novo papel que ele concedeu às autoridades tradicionais) para fins eleitorais, massificando a cultura. Dentro deste projeto de exaltação da "unidade na diversidade", existe todavia uma diversidade (mesmo de tipo artístico e cultural) que não é admitida, apesar dos princípios constitucionais extremamente democráticos. Se trata da diversidade de ideias em relação ao seu projeto político. Muitos artistas (por exemplo o rapper Azagaia), jornalistas, intelectuais serão perseguidos e processados ao longo da governação de Guebuza por não serem alinhados com as ideias do presidente. Uma mistura de nacionalismo, autoritarismo, valorização das identidades locais carateriza portanto este último (pelo menos para os efeitos deste artigo) período das políticas culturais.

Hoje, várias dificuldades na implementação das políticas culturais continuam, pois a nível do governo ainda não existe um sistema nacional que possa organizar os recursos e as informações a partir do governo central para as provinciais, os distritos, as cidades a as localidades. Por fim, nas zonas rurais e urbanas, as populações continuam a construir, produzir e criar valores e tradições de extrema importância para o país, sem recursos financeiros e a falta de instituição pública soberana em seu território. Por isso que a difusão do seu trabalho para fora dos confins de uma aldeia ou de um distrito quase nunca acontece, com grande desperdiço de valor cultural e artístico que poderia representar um grande instrumento para o desenvolvimento do país. 


\section{Referências}

ABDALA, Amina \& MURRURE, Télio. (2016). Carta de Moçambique a Tutela dos Direitos de Autor no Âmbito das Actividades Publicitárias no Ordenamento Jurídico Moçambicano. Propriedades Intelectuais, $\mathrm{n}^{\circ}$ 6, p. $69-70$.

ALEMAZUNGH, J.A. (2010). Post-Colonial Colonialism: An Analysis of International Factors and Actors Marring African Socio-Economic and Political Development. The Journal of Pan African Studies, vol.3, n.10, p. 62-84. Disponível em:

http://www.jpanafrican.org/docs/vol3no10/3.10Post-Colonial.pdf. Acesso: 10/05/2020

ANTÓNIO, Elsa Maria Da Silva. (2017). Contribuição Da ONU para os Direitos Humanos em Moçambique. Dissertação apresentada à Universidade Lusófona de Humanidades e Tecnologias, para a obtenção do grau de Mestre. Lisboa

AWINSONG, Moses Allor. (2017). The Colonial and Post-Colonial Transformation of African Chieftaincy: A Historiography. Disponíve em:

https://www.eiu.edu/historia/Awinsong2017.pdf. Acesso: 10/05/2020

BARRETO, Isabel. (2010). Independência e Criação de Heróis Nacionais: Exemplos de Moçambique. Revista Contemporânea, $n^{\circ}$ 1, p. 203-221.

BASÍLIO, Guilherme. (2011). Samora Machel: O princípio do Homem Novo e seus significados. Revista da Universidade Pedagógica.

BORGES, Edson. (2001). A Política Cultural em Moçambique Após a Independência (19751982). Rio de Janeiro: Editora UFRJ.

BOTELHO, Isaura. (1997). A Diversificação das Fontes de Financiamento para a Cultura: Um Desafio para os Poderes Públicos. Rio de Janeiro: FUNARTE.

CAMBAZA, Virgílio. (2009). A Lei de Terras, Minas e Sistemas de Direitos Consuetudinários. Maputo: Instituto de Estudos Sociais e Económicos.

CAPPELEN, Christoffer \& SORENS, Jason. (2018). Pre-colonial centralisation, traditional indirect rule, and state capacity in Africa. Commonwealth and Comparative Politics, Vol. 56, Issue 2, p. 195-215

CHIZIANE, Paulina \& MARTINS, Mariana. (2016). Ngoma Yethu: O Curandeiro e o Novo Testamento. Maputo: Matiko 
FELICIANO, José Fialho. (1998). Antropologia Económica dos Thonga do Sul de Moçambique. Maputo: Arquivo Histórico de Moçambique

GONÇALVES, Nuno Simão; LOPES, Nuno \& ROSSA, Walter. (2018). Oficinas de Muhipi: Planeamento Estratégico, Património, Desenvolvimento. Coimbra: Imprensa da Universidade de Coimbra.

LANDGRAF, Flávia Landucci. (2014). Políticas culturais em Moçambique: do Estado Socialista ao Aberto à Economia de Mercado. Trabalho de Conclusão de curso apresentado ao Centro de Estudos Latino-Americanos sobre Cultura e Comunicação da Escola de Comunicações e Artes da Universidade de São Paulo para a obtenção do título de Especialista em Gestão de Projetos Culturais e Organização de Eventos. São Paulo.

LOPES, Pedro Pereira. (2016). Políticas Culturais em Moçambique: Quando há Pouca Luz no Fundo do Túnel Disponível em https://www.academia.edu/23190590/Pol\%C3\%ADticas Culturais em Mo\%C3\%A7ambi que Quando h\%C3\%A1 Pouca Luz no Fundo do T\%C3\%BAnel. Acesso em 5 de Maio de 2019.

INLIA, Marcelina Júlio (2016). Moçambique pôs independência (1975-1987). Monografia apresentada à Universidade Pedagógica para a obtenção do grau de Licenciatura. Quelimane: UP

JOÃO, Angélica \& CHONGO, Edith. (2015). Moçambique, 40 Anos de Independência: Unidade Nacional, Paz e Progresso. Maputo: ARPAC.

MABONGO, António William. (2015). Diversidade Étnica e Exclusão Social no Processo da Consolidação da Unidade Nacional: O Caso dos Vendedores e Vendedoras Informais do Mercado de Estrela Vermelha. Dissertação apresentada à Universidade Aberta para a obtenção do grau de Mestre. São Paulo.

MALOA, Tomé Miranda. (2016). História da Economia Socialista Moçambicana. Dissertação apresentada à Universidade de São Paulo para a obtenção do grau de Mestre. São Paulo.

MARTINS, P.H. (2019). Teoria Crítica da Colonialidade. Rio de Janeiro: Ateliê de Humanidades

MATEUS, Dalila Cabrita \& MATEUS, Álvaro. (2010). Nacionalistas Moçambique. Córdova: Textos Editores

MAZRUI, Ali A. \& WONDJI, Christophe (Eds.), (2010). História Geral da África VIII. Brasília: UNESCO

MINISTÉRIO DA EDUCAÇÃO E CULTURA (2017). Colectânea da Legislação Cultural de Moçambique. Maputo: Direcção Nacional da Cultura. 
MOÇAMBIQUE (2008). Comunicação de Sua Excelência Armando Emílio Guebuza, Presidente da República de Moçambique, por ocasião da Abertura do V Festival Nacional da Cultura. Xai-Xai, 11 de Julho de 2008. Maputo

MOÇAMBIQUE (2004). Constituição da República de Moçambique. Maputo: Imprensa Nacional

NASSABE, Jonas \& MANDLATE, Teixeira (2011). Estatística da Cultura, 2011. Maputo: Instituto Nacional de Estatística

MOSCA, João (2005). Economia de Moçambique. Lisboa: Editora Piaget

OMAR, Lúcia Laurentina \& JÚNIOR, Euler Sandeville. (2015). Património Cultural e Memória Social na Ilha de Moçambique. Revista CPC, n.18, p. 4-28.

PAREDES, Marçal de Menezez. (2014). A Construção da Identidade Nacional Moçambicana no Pós-Independência: Sua Complexidade e Alguns Problemas de Pesquisa. Anos 90, v. 21, $\mathrm{n}^{\circ}$ 40, p. 131-161.

PEHRSSON, Kajsa. (2001). Avaliação do Apoio Sueco à Cultura em Moçambique. Stokholm: SIDA.

PIRES, Maria José Morais. (1999). Carta Africana dos Direitos Humanos e dos Povos. Documentação e Direito Comprado, 79/80, p. 335-350.

Resolução n 12/97 (Aprova a Política Cultural e Estratégia de sua Implementação em Moçambique)

REPÚBLICA DE MOÇAMBIQUE. (2014). Estratégia Nacional de Desenvolvimento (20152035). Maputo

SENZENE, António Leuane. (2017). Legislação Sobre a Protecção do Património Cultural da Libertação Nacional em Moçambique. Monografia apresentada na Universidade Eduardo, para a obtenção do grau de Licenciatura. Maputo: UEM

SKINNER, Elliott P. (1998). African Political Cultures and the Problems of Government. African Studies Quarterly. Vol. 2, Issue 3, p. 17-25. Disponível em: http://asq.africa.ufl.edu/files/ASQ-Vol-2-Issue-3-Skinner.pdf

SOUSA, Luís Manuel Manana. (2010). Interações Culturais. Caderno de Investigação Aplicada, $n^{\circ} 4$, p. 133-151

UNESCO (2003). Convenção de Paris para a Salvaguarda do Património Cultural Imaterial. Disponível em: http://www.portal.iphan.gov.br/uploads/ckfinder/arquivos/convencaoSalvaguarda.pdf 